\title{
FERTIRRIGAÇÃO NITROGENADA NA CULTURA DO FEIJOEIRO (Phaseolus vulgaris L.) POR SISTEMA DE IRRIGAÇÃO POR ASPERSÃO
}

\author{
Décio Eugênio Cruciani ${ }^{1}$, Pedro César Soares Maia ${ }^{2}$, \\ Vital Pedro da Silva Paz ${ }^{3}$ José Antonio Frizzone ${ }^{4}$
}

\begin{abstract}
RESUMO
O objetivo deste trabalho foi avaliar o efeito da adubação nitrogenada, aplicada através da água de irrigação sobre o rendimento de grãos, acúmulo de matéria seca e absorção de nitrogênio pelo feijoeiro (Phaseolus vulgaris L.). O delineamento estatístico foi o de blocos casualizados, com parcelas subdivididas e cinco repetições e a fonte utilizada de nitrogênio foi uréia, aplicada a uma taxa de $40 \mathrm{~kg} / \mathrm{ha}$. Os tratamentos foram: i) parcelas sem adubação de cobertura; ii) parcelas com adubação de cobertura, aplicada manualmente em dosagem única aos 30 dias após a germinação; e iii) adubação nitrogenada de cobertura, aplicada através da água de irrigação, aos 30, 42 e 50 dias após a germinação. A análise dos resultados permitiu concluir que a adubação nitrogenada aumentou significativamente a produção de grãos e a absorção de nitrogênio pela planta e, quando aplicada parceladamente, através da água de irrigação, proporcionou melhores resultados em relação à aplicação de uma só vez e manualmente.
\end{abstract}

Palavras-chave: irrigação, nitrogênio, feijoeiro

\section{NITROGEN FERTIRRIGATION OF BEAN (Phaseolus vulgaris L) CROP BY SPRINKLE IRRIGATION SYSTEM}

\begin{abstract}
The objective of this research was to evaluate the effect of nitrogen fertilization, applied through irrigation water, on grain yield, dry matter production and nitrogen absorption by bean crop (Phaseolus vulgaris $\mathrm{L}$ ). The statistical design was the randomized blocks with split plots and five repetitions. Urea fertilizer was used as the nitrogen resource, applied at a rate of $40 \mathrm{~kg} / \mathrm{ha}$. The treatments were: i) plots without nitrogen fertilizer covering the soil surface; ii) plots with nitrogen fertilizer covering the soil surface, applied once manually 30 days after germination; iii) plots with nitrogen solution applied by sprinkle irrigation water at 30,42 and 50 days after germination. The results showed that nitrogen fertilization increased significantly the grain yield and nitrogen absorption by plants. The nitrogen fertilization applied through irrigation water favored better results, comparing to the one applied at once and manually.
\end{abstract}

Key words: irrigation, nitrogen, bean

\footnotetext{
${ }^{1}$ Prof. Titular - Departamento de Engenharia Rural -ESALQ/USP, Av. Pádua Dias 11 - CP 9. 13418-900 - Piracicaba-SP. Fone (019) 429-4217. E-mail: cruciani@ carpa.ciagri.usp.br

${ }^{2}$ Eng. Agrônomo, Mestre em Irrigação e Drenagem, CODEVASF.

${ }^{3}$ Eng. Agríc., Doutor em Irrigação e Drenagem, bolsista da FAPESP, Departamento de Engenharia Rural - ESALQ/USP.

E-mail: vpspaz@carpa.ciagri.usp.br

${ }^{4}$ Prof. Associado - Departamento de Engenharia Rural-ESALQ/USP, E-mail: frizzone@ carpa.ciagri.usp.br
} 


\section{INTRODUÇÃO}

A baixa produtividade na exploração da cultura do feijoeiro no Brasil é oriunda de várias causas, como: da utilização de sementes de qualidade imprópria, da adubação inadequada, do controle deficiente de pragas e doenças, da adversidade climática nas lavouras conduzidas em regime de sequeiro e da falta ou do excesso de água em períodos críticos de desenvolvimento das plantas.

Dentre os elementos que influenciam o desenvolvimento das plantas, o nitrogênio é de vital importância e, embora seja o mais abundante na natureza, representando cerca de $78 \%$ da composição do ar atmosférico, é o elemento que mais limita a produção das culturas, pois na forma gasosa não é disponível para a maioria das plantas (Neves, 1981).

Segundo Malavolta (1981) para a fertirrigação nitrogenada têm sido utilizadas várias fontes comerciais de nitrogênio, obtidas a partir do nitrogênio do ar por fixação industrial, como uréia, sulfato de amônio, nitrato de amônio, etc. A uréia representa uma das fontes mais econômicas de nitrogênio, sendo completamente assimilável pelas plantas, nas formas amoniacal e nítrica.

As perdas de nitrogênio para a atmosfera se dão na forma de amônia $\left(\mathrm{NH}_{3}\right)$ e ocorrem com alta freqüência quando o adubo é aplicado na superfície do solo sem incorporação. Umidade, temperatura, $\mathrm{pH}$, complexo de troca e teor de matéria orgânica, dentre outros fatores, influenciam a perda de nitrogênio para a atmosfera (Malavolta, 1981). Rodrigues \& Kiehl (1986) avaliando formas de aplicação de uréia em laboratório e em casa de vegetação, com aplicação na superfície do solo, concluíram que a aplicação na superfície resultou na volatilização de quase todo o nitrogênio. Melhor controle foi verificado quando se incorporou o fertilizante a uma profundidade maior.

Malavolta (1980) descreveu a conveniência do parcelamento do nitrogênio em função da baixa exigência inicial da cultura. As culturas anuais devem receber, no plantio, apenas uma fração da dose de nitrogênio de que necessitam, aplicando-se o restante sobre o solo, ao lado da planta, no período de sua maior exigência. A uréia, quando utilizada como fonte de nitrogênio, deve ser incorporada visando evitar perdas por volatilização, as quais podem atingir 25 a $60 \%$ do total aplicado. Meirelles et al. (1980) trabalhando com adubação nitrogenada em feijoeiro em Terra Roxa Estruturada e usando o sulfato de amônio como fonte de nitrogênio obtiveram, com a aplicação de $100 \mathrm{~kg} . \mathrm{ha}^{-1}$, um aproveitamento de $30 \mathrm{~kg} \cdot \mathrm{ha}^{-1}$ de nitrogênio e concluíram que a adubação nitrogenada deve ser parcelada, aplicando-se 1/3 da dose no plantio e 2/3 aos 30 ou 45 dias após a germinação.

Costa et al. (1986) citaram que a fertirrigação apresenta, como vantagens, a economia de mão-de-obra e maquinaria, aplicação no momento exato em que a planta necessita, possibilidade de aplicação em qualquer fase do ciclo da cultura, fácil fracionamento e controle da quantidade de fertilizante aplicado, distribuição mais uniforme, maior eficiência de utilização dos nutrientes e menor dano físico ao solo e à cultura.

Frizzone et al. (1985) observaram que a aplicação mecânica de fertilizantes é relativamente demorada e, em alguns casos, provoca a compactação do solo. A fertirrigação é bastante rápida e cômoda e a solução de fertilizante dilui-se de forma homogênea na água de irrigação, distribuindo-se na área da mesma forma que a água.
Rehm \& Wiese (1975) conduziram um experimento para avaliar a influência do método de aplicação de nitrogênio em relação à textura do solo e concluíram que a aplicação de nitrogênio via água de irrigação por aspersão, aumentou a produção de grãos de milho no solo arenoso. Para o solo com textura fina, na profundidade de 50 a $70 \mathrm{~cm}$, o método de aplicação não influenciou a produção.

O objetivo deste trabalho foi avaliar a aplicação do fertilizante nitrogenado pelo sistema de irrigação por aspersão, na cultura do feijoeiro, em comparação com o método manual e adubação de cobertura.

\section{MATERIAL E MÉTODOS}

Este trabalho foi realizado na área experimental do Departamento de Engenharia Rural da Escola Superior de Agricultura "Luiz de Queiroz"/USP, em solo classificado como Terra Roxa Estruturada (Ranzani et al., 1966). A caracterização física do solo da área experimental foi realizada a partir de amostras coletadas em diferentes camadas do perfil, determinando-se a composição granulométrica, a densidade global e as curvas de retenção de água. Para se avaliar as necessidades nutricionais ou corretivas para o estabelecimento da cultura no solo, procedeu-se à determinação de teores de matéria orgânica, fósforo, potássio, alumínio, magnésio e $\mathrm{pH}$.

A cultura utilizada foi o feijoeiro (Phaseolus vulgaris L.) cultivar carioca. O delineamento experimental foi o de blocos casualizados, com parcelas subdivididas, três tratamentos e cinco repetições e quatro épocas de coleta para análise. A parcela experimental consistia de uma área de $64 \mathrm{~m}^{2}(8 \mathrm{~m}$ x $8 \mathrm{~m})$ em cuja parte central foi demarcada uma área útil de $16 \mathrm{~m}^{2}(4 \mathrm{~m} \times 4 \mathrm{~m})$. Os tratamentos foram: aplicação de $13,33 \mathrm{~kg}_{\mathrm{h}} \mathrm{ha}^{-1}$ de nitrogênio 5 dias após a germinação, sem adubação de cobertura (T1); aplicação de $13,33 \mathrm{~kg} \cdot$ ha $^{-1}$ de nitrogênio 5 dias após a germinação, com adubação de cobertura de $26,67 \mathrm{~kg} \cdot \mathrm{ha}^{-1}$ de nitrogênio aplicados manualmente, em uma única dose 30 dias após a germinação (T2); aplicação de 13,33kg.ha-1 de nitrogênio 5 dias após a germinação, com adubação de cobertura parcelada em 8,0, 10,67 e 8,0kg.ha ${ }^{-1}$ de nitrogênio aos 30, 42 e 50 dias após a germinação, aplicados em fertirrigação. As amostragens das plantas foram realizadas aos: (E1) 30, (E2) 42, (E3) 50 e (E4) 60 dias após a germinação e o fracionamento da adubação nitrogenada foi realizado com base nos resultados obtidos por Haag \& Malavolta (1967) e Urquiaga (1982) utilizando-se a uréia como fonte de nitrogênio.

A aplicação da água de irrigação e, conseqüentemente, da solução de fertilizante, foi realizada pelo sistema de irrigação por aspersão convencional. Para controle da irrigação utilizaram-se tensiômetros instalados no solo nas profundidades de 15 e $25 \mathrm{~cm}$, para informações do potencial matricial, segundo Van Genutchen (1980). Definiu-se o potencial matricial de -58,848 KPa como limite inferior da disponibilidade real de água no solo. O fertilizante nitrogenado foi introduzido no sistema de irrigação por meio de um injetor de fertilizante de funcionamento hidráulico e o volume injetado foi regulado por um registro de controle de admissão de água. O tratamento com fertirrigação foi realizado aplicando-se, inicialmente, uma lâmina de água, seguida da solução fertilizante e, ao final, uma outra lâmina de água.

A quantidade de fertilizante sólido fornecido à rede de distribuição de água foi estimada pela expressão: 


$$
Q F T=\frac{(C D S C S I C T)}{(C I B P N F)}
$$

em que:

QFT - quantidade de fertilizante sólido a ser colocado no tanque, g

CDS - concentração desejada na solução do fertilizante na água de irrigação, ppm

CSI - vazão do sistema de irrigação, $\mathrm{m}^{3} \cdot \mathrm{h}^{-1}$

CT - volume do tanque, $\mathrm{m}^{3}$

CIB - capacidade de injeção da bomba injetora, $\mathrm{m}^{3} \cdot \mathrm{h}^{-1}$

PNF - porcentagem do nutriente no fertilizante, decimal.

Para análise do nitrogênio total na planta foram realizadas amostragens nas parcelas aos 30, 42 e 50 e 60 dias após a germinação, retirando-se plantas ao caso em cada parcela, e o material colhido enviado para laboratório. Procedeu-se à digestão sulfúrica em amostras de 100mg de material colhido.

As quantidades de nitrogênio total extraídas pelas plantas nas diferentes épocas de desenvolvimento foram calculadas pela expressão:

$$
Q N T P=\frac{(\% N T P M V S)}{100}
$$

em que:

QNTP - quantidade de nitrogênio total na planta, em kg.ha-1

$\%$ NTP - porcentagem de nitrogênio total na planta

MVS - rendimento do material vegetal seco, em $\mathrm{kgha}^{-1}$.

Aos 87 dias após a germinação, efetuou-se a colheita manual das plantas para avaliação da produtividade. Foi determinada a umidade dos grãos e feita a correção para 13\%, pela equação:

$$
P f=\frac{[P i(100-U)]}{(100-U f)}
$$

em que:

Pf - massa final de grãos, $\mathrm{kg}$

$\mathrm{Pi}$ - massa inicial de grãos, $\mathrm{kg}$

U - teor inicial de água na semente (\%) em base úmida

Uf - teor final de água na semente (\%) em base úmida

\section{RESULTADOS E DISCUSSÃO}

\section{Rendimento de matéria seca}

As análises estatísticas do rendimento de matéria seca do feijoeiro são apresentadas nas Tabelas 1 e 2, e na Figura 1 , está a representação do rendimento de matéria seca.

A análise de variância indica uma diferença significativa entre os tratamentos para acúmulo de matéria seca, a nível de significância de 2,08\% (Tabela 1). A interação tratamento $\mathrm{x}$ épocas de análise foi significativa a $1,15 \%$, indicando a ocorrência de diferença entre os tratamentos, em cada época de desenvolvimento da cultura.

Considerando-se as médias dos tratamentos (Tabela 2) observa-se que aos 30 e 42 dias após a germinação não ocorreu diferença significativa a nível de $5 \%$ de probabilidade entre os tratamentos, o que permite inferir que, para este período, a produção de matéria seca não foi influenciada pelos diferentes tratamentos.
Tabela 1. Análise de variância do rendimento de matéria seca do feijoeiro

\begin{tabular}{lccccc}
\hline Causas de variação & G.L. & S.Q. & Q.M. & F & Probabilidade. \\
\hline Blocos & 4 & 3,4164 & & & \\
Tratamentos & 2 & 6,3497 & 3,1749 & 6,5315 & 0,02076 \\
Resíduo (a) & 8 & 3,8887 & 0,4861 & & \\
\hline Parcelas & 14 & 13,6548 & & & \\
\hline Épocas & 3 & 75,7846 & 25,2615 & 105,9948 & 0,0001 \\
Tratamentos x épocas & 6 & 4,6717 & 0,7786 & 3,2670 & 0,01147 \\
Resíduo (b) & 36 & 8,5798 & 0,2383 & & \\
\hline Total & 59 & 102,6909 & & & \\
\hline
\end{tabular}

\begin{tabular}{|c|c|}
\hline \multicolumn{2}{|c|}{30 dias após a germinação } \\
\hline Tratamento & Média $\left(\mathrm{kg} \cdot \mathrm{ha}^{-1}\right)$ \\
\hline Fertirrigação & 1016,0 a $\mathrm{A}$ \\
\hline Adubação convencional & 863,2 a $\mathrm{A}$ \\
\hline Testemunha & 809,0 a $\mathrm{A}$ \\
\hline \multicolumn{2}{|c|}{42 dias após a germinação } \\
\hline Tratamento & Média $\left(\mathrm{kg} \cdot \mathrm{ha}^{-1}\right)$ \\
\hline Fertirrigação & 1971,6 a $\mathrm{A}$ \\
\hline Adubação convencional & 1643,6 a $\mathrm{A}$ \\
\hline Testemunha & 1651,2 a $\mathrm{A}$ \\
\hline \multicolumn{2}{|c|}{50 dias após a germinação } \\
\hline Tratamento & Média $\left(\mathrm{kg} \cdot \mathrm{ha}^{-1}\right)$ \\
\hline Fertirrigação & 2861,2 a A \\
\hline Adubação convencional & $2812,8 \mathrm{ab} \mathrm{A}$ \\
\hline Testemunha & 2053,4 b A \\
\hline \multicolumn{2}{|c|}{60 dias após a germinação } \\
\hline Tratamento & Média $\left(\mathrm{kg} \cdot \mathrm{ha}^{-1}\right)$ \\
\hline Fertirrigação & 4837,0 a $\mathrm{A}$ \\
\hline Adubação convencional & $4005,0 \mathrm{~b} \mathrm{~A}$ \\
\hline Testemunha & 2995,6 с B \\
\hline
\end{tabular}

Tabela 2. Teste de Tukey para o rendimento de matéria seca $\left(\mathrm{kg} \mathrm{ha}^{-1}\right)$ do feijoeiro.

Médias seguidas por letras distintas, minúsculas, diferem a nível de significância de 5\% (D.M.S. $=77,30$ Médias seguidas por letras distintas, maiúsculas, diferem a nível de significância de 1\% DMS (1\%)=99,50

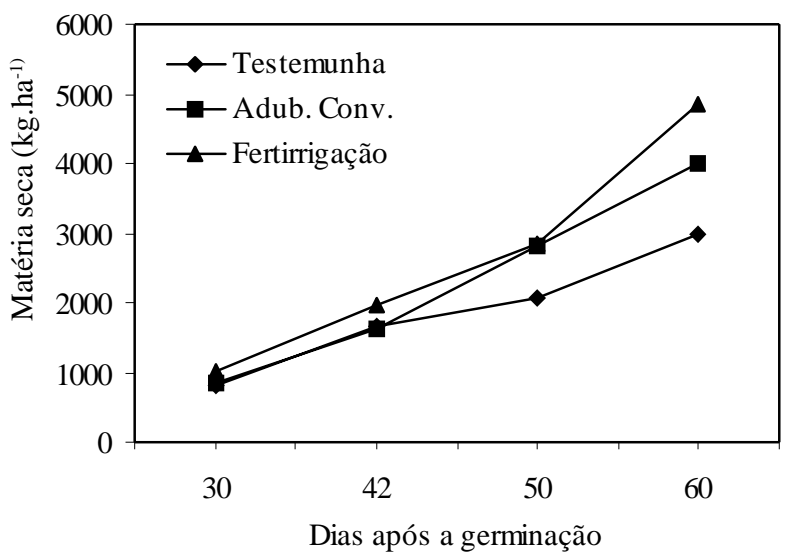

Figura 1. Rendimento médio de matéria seca do feijoeiro sob diferentes tratamentos de adubação nitrogenada

Analisando-se a época de amostragem de 50 dias após a germinação, verifica-se que os tratamentos com adubação 
nitrogenada convencional e fertirrigação não diferiram a nível de 5\%, mas a aplicação de nitrogênio através da água de irrigação foi significativa a esse nível de probabilidade, em relação ao tratamento testemunha (sem adubação de cobertura). Para 60 dias após a germinação foi observada diferença significativa a nível de 5\% entre os tratamentos, indicando resposta favorável à adubação nitrogenada em cobertura, tanto para a aplicação convencional como para a fertirrigação, cujos resultados apresentam coerência com aqueles obtidos por Meirelles et al. (1980) e Urquiaga (1982) em que a aplicação parcelada propiciou maior eficiência de utilização do fertilizante nitrogenado.

\section{Nitrogênio na planta}

Os resultados da análise de variância da quantidade de nitrogênio absorvido estão apresentados na Tabela 3, na qual se observa que a adubação nitrogenada incrementou significativamente a quantidade de nitrogênio absorvido pela planta a nível de 4,27\%, e que a interação tratamento x época de análise, também apresentou-se significativa a nível de 1,72\% de probabilidade.

Tabela 3. Análise de variância da quantidade de nitrogênio absorvido $\left(\mathrm{kg} \cdot \mathrm{ha}^{-1}\right)$ pelo feijoeiro

\begin{tabular}{lccccc}
\hline Causas de variação & G.L. & S.Q. & Q.M. & F & Probabilidade \\
\hline Blocos & 4 & 5182,7497 & & & \\
Tratamentos & 2 & 6879,3719 & 3439,6860 & 4,8280 & 0,0417 \\
Resíduo (a) & 8 & 5699,5608 & 712,4451 & & \\
\hline Parcelas & 14 & 17761,6824 & & & \\
\hline Épocas & 3 & 42443,9027 & 14147,967 & 53,6038 & 0,00001 \\
Tratamentos x épocas & 6 & 4766,7662 & 794,4610 & 3,0101 & 0,01719 \\
Resíduo (b) & 36 & 9501,6552 & 263,9360 & & \\
\hline TOTAL & 59 & 74474,0065 & & & \\
\hline
\end{tabular}

Analisando-se os valores médios de nitrogênio absorvido (Tabela 4) verifica-se que para as épocas de 30 e de 42 dias após a germinação, não ocorreram diferenças significativas em nível de 5\% para as quantidades de nitrogênio absorvidas nos diferentes tratamentos. Pode-se inferir, portanto, que até 42 dias após a germinação o nitrogênio fornecido pelo solo foi suficiente para atender às necessidades das plantas. Para as épocas de 50 e 60 dias após a germinação, não foi observada diferença significativa a nível de 5\%, para as quantidades absorvidas, entre os tratamentos adubação nitrogenada convencional e fertirrigação. Este fato pode estar relacionado à quantidade de nitrogênio prontamente disponível no solo, a 50 e 60 dias após a germinação; em ambos os tratamentos, o nitrogênio absorvido foi significativamente maior que na testemunha.

\section{Rendimento de grãos}

As análises do rendimento de grãos do feijoeiro estão apresentadas nas Tabelas 5 e 6, em que se verifica, pela análise de variância, a existência de diferença entre os tratamentos, a nível de 1,85\%. Aplicando-se o teste de Tukey, observa-se que não ocorreu diferença significativa a nível de 5\% de probabilidade entre os tratamentos fertirrigação e adubação convencional, mas os mesmos apresentaram diferença a nível de 5\% em relação ao tratamento testemunha.
Tabela 4. Teste de Tukey para quantidade de nitrogênio absorvido (kg.ha- $\left.{ }^{-1}\right)$ pelo feijoeiro.

\section{0 dias após a germinação}

\begin{tabular}{lc}
\hline Tratamento & Média $\left(\mathrm{kg} \cdot \mathrm{ha}^{-1}\right)$ \\
\hline Fertirrigação & 38,626 a A \\
Adubação convencional & 35,248 a A \\
Testemunha & 32,298 a A
\end{tabular}

42 dias após a germinação

\begin{tabular}{lc}
\hline Tratamento & Média $\left({\left.\mathrm{kg} \cdot h \mathrm{~h}^{-1}\right)}^{60,582 \text { a A }}\right.$ \\
\hline Fertirrigação & 73,582 a A \\
Adubação convencional & 55,238 a A \\
Testemunha
\end{tabular}

50 dias após a germinação

\begin{tabular}{lc}
\hline Tratamento & Média $\left(\mathrm{kg}^{\circ} \cdot \mathrm{ha}^{-1}\right)$ \\
\hline Fertirrigação & 91,622 a A \\
Adubação convencional & 90,046 a A \\
Testemunha & 60,222 b A \\
\hline
\end{tabular}

60 dias após a germinação

\begin{tabular}{lc}
\hline Tratamento & Média $\left(\mathrm{kg} \cdot \mathrm{ha}^{-1}\right)$ \\
\hline Fertirrigação & 134,818 a A \\
Adubação convencional & 110,742 a AB \\
Testemunha & 80,148 b B
\end{tabular}

Médias seguidas por letras distintas, minúsculas, diferem a nível de significância de 5\% (D.M.S. $=28,0941$ ) Médias seguidas por letras distintas, maiúsculas, diferem a nível de significância de 1\% DMS $(1 \%)=36,3629$

Tabela 5. Análise de variância do rendimento de grãos do feijoeiro

\begin{tabular}{lccccc}
\hline Causas de variação & G.L. & S.Q. & Q.M. & F & Probabilidade \\
\hline Blocos & 4 & 249828,4000 & & & \\
Tratamentos & 2 & 212766,2666 & 124914,2000 & 6,8409 & 0,01854 \\
Resíduo & 8 & 146078,9333 & 18259,8666 & & \\
\hline TOTAL & 14 & 608673,6000 & & &
\end{tabular}

Tabela 6. Teste de Tukey para rendimento de grãos do feijoeiro

Tratamento Rendimento médio (kg/ha)

Fertirrigação

1100,4 a $\mathrm{A}$

Adubação convencional

1059,8 a $\mathrm{A}$

Testemunha

808,6 b A

Médias seguidas por letras distintas, minúsculas, diferem a nível de significância de 5\% (D.M.S. $=244,1435)$ Médias seguidas por letras distintas, maiúsculas, diferem a nível de significância de 1\% DMS (1\%) =340,8340

A adubação nitrogenada em cobertura incrementou a produção de grãos em $36,09 \%$ e $31,07 \%$, respectivamente, para a fertirrigação e a adubação nitrogenada convencional, em relação à testemunha. A não ocorrência de diferença significativa, pelo teste de Tukey, na produção de grãos entre os tratamentos fertirrigação e adubação nitrogenada convencional, permite inferir que as perdas de nitrogênio aplicado através da adubação convencional foram restritas, indicando que a textura fina do solo possivelmente limitou as perdas por lixiviação. Esses resultados estão de acordo com Rehm \& Wiese (1975) e Hagin $\&$ Tucker (1982). 


\section{CONCLUSÕES}

1. A adubação nitrogenada em cobertura aumentou significativamente, a nível de $5 \%$ de probabilidade, a produção de grãos e a absorção de nitrogênio pela planta.

2. Os tratamentos fertirrigação e adubação nitrogenada convencional, não apresentaram diferença significativa a nível de 5\% de probabilidade, para a absorção de nitrogênio e produção de grãos.

3. A adubação nitrogenada aplicada parceladamente através da água de irrigação proporcionou melhores resultados em relação à aplicação de uma só vez e manualmente.

\section{REFERÊNCIAS BIBLIOGRÁFICAS}

COSTA, E.F.; FRANÇA, G.E.; ALVES, V.M. Aplicação de fertilizantes via água de irrigação. Informe Agropecuário, Belo Horizonte, v.12, n.39,p.63-8. 1986.

FRIZZONE, J.A.;ZANINI, J.R.; PAES, L.A.D.; NASCIMENTO, V.M. do. Fertirrigação mineral. Ilha Solteira, UNESP, 1985. 52p. (Boletim técnico 2).

HAAG, H.P.; MALAVOLTA, E. Absorção de nutrientes pela cultura do feijoeiro. Bragantia, Campinas,v.26,p.381-91. 1967.

HAGIN, J.; TUCKER, B. Fertilization of dryland and irrigated soils. Berlin, Springer-Verlag, 1982. 190p.

MALAVOLTA, E. Elementos de nutrição mineral de plantas. São Paulo, Ed. Ceres, 1980.252p.
MALAVOLTA, E. Manual de química agrícola. adubos e adubação. São Paulo, $3^{\mathrm{a}}$ ed. Ceres, 1981. 607p.

MEIRELLES, N.M.; LIBARDI, P.L.; REICHARDT, K. Absorção e lixiviação de nitrogênio em uma cultura de feijão (Phaseolus vulgaris, L). Revista Brasileira de Ciência do Solo, Campinas, v.4, p.83-8.1980.

NEVES, M.C.P. Interdependência fisiológica entre os componentes do sistema simbiótico Rhizobium Leguminosas. Revista Brasileira de Ciência do Solo, Campinas, v.5,p.79-92. 1981.

RANZANI, G.; FREIRE, O.; KINJO, K. Levantamento da carta de solos do município de Piracicaba. Piracicaba, ESALQ/ USP, 1966. 85p.

REHM, G.M.; WIESE, R.A. Effect of method of nitrogen application on corn (Zea mays, L) growth on irrigated sand soils. Soil Science Society of America, v.32,n.6,p.1217-20. 1975.

RODRIGUES, M.B.; KIEL, J.L. Volatilização da amônia após uréia em diferentes doses de aplicação. Revista Brasileira de Ciência do Solo, Campinas, v.10,n.1,p.37. 1986.

URQUIAGA, S.U. Dinâmica do nitrogênio no sistema soloplanta na cultura do feijão (Phaseolus vulgaris, $L$ ) cultivar carioca. Piracicaba, ESALQ/USP, 1982. 154p. (Tese de Doutoramento).

VAN GENUTCHEN, M. Th. A closed-form equation for predicting the hydraulic conductivity of unsatured soil. Soil Sciency. Society America Journal, Madison, v.44,p.892-898. 1980. 